\title{
Assessment of aberrations and visual quality differences between myopic and astigmatic eyes before and after contact lens application
}

\author{
Mustafa Demir ${ }^{1}$, Sevda Aydin Kurna ${ }^{1}$, Tomris Sengor ${ }^{2}$, \\ Tugba Gencaga Atakan', Tayfun Sahin ${ }^{1}$ \\ ${ }^{1}$ Department of Ophthalmology, Fatih Sultan Mehmet Training and Research Hospital, Istanbul, Turkey \\ ${ }^{2}$ Department of Ophthalmology, Bilim University Faculty of Medicine, Istanbul, Turkey
}

\begin{abstract}
OBJECTIVE: To evaluate the aberration and visual quality differences between myopic and astigmatic eyes before and after contact lens application by using corneal aberrometer and low- contrast sensitivity chart.

METHODS: Eighty eyes of 40 patients were included in this study. Patients were divided into two groups as myopic (40 eyes, $n=20$ ) and astigmatic groups (40 eyes, $n=20$ ). We used aspheric Balafilcon A (Purevision and Purevision Toric Bausch\&Lomb, Rochester, USA) lenses for each group. Corneal aberrations and low-contrast sensitivity values were measured and compared for each patient in both groups.

RESULTS: There were no statistically significant differences between myopic and astigmatic groups when we compared low-contrast sensitivity values for both on- and off-eyes. Mean total higher-order aberration (HOA) values for off-eye, were $0.29 \pm 0.10 \mu \mathrm{m}$, and $0.33 \pm 0.10 \mu \mathrm{m}$ for on-eye in the myopic group, while they were $0.42 \pm 0.14 \mu \mathrm{m}$ in off-eye and $0.37 \pm 0.23 \mu \mathrm{m}$ in on-eye in the astigmatic group. Off-eye mean coma, irregular astigmatism and total higher-order aberration RMS (root-mean-square) values were significantly higher in the astigmatic group compared to the myopic group ( $p=0.006, p=0.001, p=0.001$ ) but mean on-eye RMS values were not.

CONCLUSION: Myopic and astigmatic patients differ in terms of high-order aberrations and these differences cannot be equalized after contact lens application, but visual quality can be improved in both patients by using contact lenses.
\end{abstract}

Key words: Astigmatism; contact lens; corneal aberrations; myopia; visual quality.

Zxpansion of wavefront-sensing techniques redefined the meaning of refractive error in clinical ophthalmology [1]. Apart from conventional lower-order aberrations (such as defocus and astig- matism), retinal images can be degraded by other higher-order aberrations (spherical aberration, coma, and trefoil) [2]. Third order aberrations and upper levels are called as higher-order aberrations

Received: September 23, 2014 Accepted: February 24, 2015 Online: April 24, 2015

Correspondence: Dr. Mustafa DEMIR. Bartin Devlet Hastanesi Goz Klinigi, Merkez, Bartin, Turkey.

Tel: +90 378 - 2277258 e-mail: mustafademir2002@hotmail.com

(c) Copyright 2015 by Istanbul Northern Anatolian Association of Public Hospitals - Available online at www.kuzeyklinikleri.com 
and cannot be corrected by spherocylindirical correction [3]. Since introduction of wavefront sensing and other ray tracing technologies, higher-order aberrations can be measured more accurately even in highly aberrated eyes $[4,5]$. It is important to quantify higher-order aberrations because they effect visual acuity and retinal image quality [6].

Wearing contact lenses causes changes in the wavefront aberrations of the eye. The changes in wavefront aberrations vary substantially from eye to eye [7]. Developing contact lens technology promises much better retinal image quality by reducing higher-order aberrations [8]. The type and design of contact lens can influence the patient's quality of vision, as the lens modifies the overall optical characteristics of the visual system and the total amount of astigmatism [9]. Different studies reported different results for both myopic and toric contact lenses about their effects on higher-order aberrations. Hong et al. [10] suggested that soft contact lenses produce significant spherical aberrations,but some other studies reported that aspheric soft contact lenses provide better vision by reducing spherical aberrations $[11,12]$. It is important to note that correction of higher-order aberrations is supposed to improve retinal image quality but in practice lack of aberration does not mean best visual performance. For instance Chen et al. reported that visual system works better with its adapted higher-order aberrations which means that it is useless to change aberration at all [13].

In our study, our aim was to evaluate the aberration and visual quality differences between aspheric Balafilcon A spheric and toric lenses after lens application in the myopic and astigmatic eyes, by using corneal higher-order aberrometer and low-contrast sensitivity chart.

\section{MATERIALS AND METHODS}

Forty eyes of twenty myopic patients and forty eyes of twenty astigmatic patients were examined in our study and all patients were chosen from the cornea clinic of Fatih Sultan Mehmet Training and Research Hospital between the years 2010 and 2011. Patients with anterior surface problems, dry eye, retinal diseases, glaucoma and strabismus were excluded. We divided patients into two groups as myopic and astigmatic according to their cylinder value. Patients with more than 0.75 diopters of corneal astigmatism were accepted as astigmatic. All patients were older than 18 years and checked for contrandications for using contact lenses, ocular surface disease, retinal disease, cataract, glaucoma and any eye disease which can compromise retinal image quality. The study protocol followed the tenets of the Declaration of Helsinki. We used aspheric Balafilcon A (Purevision Bausch\&Lomb Purevision in the myopic group and Purevision Toric in the astigmatic group) lenses for each group (Table 1). Corneal wavefront aberrations were measured by dynamic skiascopy type wavefront sensored Nidek Magellan Mapper ${ }^{\oplus}$ corneal topographer. Spherical aberration, coma, trefoil, irregular astigmatism and total higher-order aberrations of mean Root Mean Square (RMS) values were measured and recorded. Low - contrast sensitivity values were measured as letters which patients could read on Bailey-Lovie chart. In first visit we made full eye exam and determined the best visual refractive correction and best fitting contact lenses for each patient.

After one week usage of best fitting contact lenses, we measured and recorded higher-order aberrations and maximum letter numbers that patients could read on Bailey-Lovie low-contrast sensitivity chart with and without contact lenses. We measured higher-order aberrations in mezopic conditions without dilation and in $5 \mathrm{~mm}$ sized pupil for each patient.

TABLE 1. Features of contact lenses

\begin{tabular}{lcc} 
Contact lens & Purevision & Purevision toric \\
\hline Lens material & Balafilcon A & Balafilcon A \\
$\mathrm{H}_{2} \mathrm{O}$ & $36 \%$ & $36 \%$ \\
Base curve & $8.6 \mathrm{~mm}$ & $8.7 \mathrm{~mm}$ \\
Diameter & $14 \mathrm{~mm}$ & $14 \mathrm{~mm}$ \\
Dk/t & 112 at $-3.00 \mathrm{D}$ & 101 at $-3.00 \mathrm{D}$ \\
Lens design & Aspheric & Aspheric
\end{tabular}


"Statistical Package for Social Sciences for Windows 17.0" (SPSS v 17) program was used to examine the data obtained in this study. Descriptive statistical methods (mean, standard deviation, proportional distribution) were used. Qualitative chi-square test was used when assessing variables. When assessing the quantitative variables independent samples t-test and paired samples t-test were used. Results were evaluated within $95 \%$ confidence interval, and at a significance level of $\mathrm{p}<0.05$.

\section{RESULTS}

Subjects included in the myopic group $(n=20)$ were between 18 and $36(24.55 \pm 4.63)$ years of age. In the astigmatic group $(n=20)$ mean age of the patients was $25 \pm 4.94$ (18-37 yrs) years. The myopic group consisted of 3 male (15\%) and 17 female (85\%), and astigmatic group comprised of 4 male (20\%) and 16 female $(80 \%)$ patients. Mean spherical refractive errors (not the spheric equivalent) in the myopic, and astigmatic groups were $-2.66 \pm 1.4$ vs $-0.37 \pm 0.12$ diopters, while corresponding mean cylindrical refractive errors were $-1.91 \pm 1.73$, and $-1.39 \pm 0.50 \mathrm{di}$ - opters, respectively ( $p>0.05)$. Best corrected visual acuity after contact lens fitting was logmar 0.0 both in myopic and astigmatic patients $(p>0.05)$.

The mean number of letters read on Bailey Lovie low- contrast sensitivity chart with, and without contact lenses were $48.82 \pm 4.98$ vs $12.37 \pm 10.66$ letters in the myopic group $(p=0.001)$. In the astigmatic group the respective mean low-contrast sensitivity values were $47.22 \pm 4.41$, and $17.0 \pm 13.94$ letters, respectively $(p=0.001)$. Statistically significant differences were not detected between myopic and astigmatic groups when we compared low-contrast sensitivity values for both on- and off-eyes, ( $p>0.05)$ (Table 2).

The mean corneal wavefront aberration values without contact lenses are shown in Table 3. The mean spherical aberration RMS values were $0.11 \pm 0.14 \mu \mathrm{m}$ in the myopic, and $0.18 \pm 0.22 \mu \mathrm{m}$ in the astigmatic groups $(p=0.111)$. Mean trefoil values were $0.11 \pm 0.07 \mu \mathrm{m}$ in the myopic, and $0.10 \pm 0.05 \mu \mathrm{m}$ in the astigmatic group $(\mathrm{p}=0.460)$. Mean coma values were $0.14 \pm 0.06 \mu \mathrm{m}$ in the myopic, and $0.19 \pm 0.09 \mu \mathrm{m}$ in the astigmatic groups

TABLE 2. Comparison of low-contrast sensitivity values off-eye and on-eye according to the groups

\begin{tabular}{lccc} 
& Off-eye & On-eye & $\mathrm{p}$ \\
\hline Myopic group & $12.37 \pm 10.66$ letters & $48.82 \pm 4.98$ letters & $0.001^{* *}$ \\
Astigmatic group & $17 \pm 13.94$ letters & $47.22 \pm 4.41$ letters & $0.001^{* *}$ \\
$\mathrm{p}$ & $0.100^{*}$ & $0.132^{*}$ & \\
\hline
\end{tabular}

**Paired T Test; *Independent T Test.

TABLE 3. Comparison of off-eye aberration values according to the groups

\begin{tabular}{lcccc} 
SPH AB & Coma & Trefoil & Total & HOA's $^{2}$ \\
\hline Myopic group & $0.11 \pm 0.14 \mu \mathrm{m}$ & $0.14 \pm 0.06 \mu \mathrm{m}$ & $0.11 \pm 0.07 \mu \mathrm{m}$ & $0.29 \pm 0.10 \mu \mathrm{m}$ \\
Astigmatic group & $0.18 \pm 0.22 \mu \mathrm{m}$ & $0.19 \pm 0.09 \mu \mathrm{m}$ & $0.10 \pm 0.05 \mu \mathrm{m}$ & $0.42 \pm 0.14 \mu \mathrm{m}$ \\
$\mathrm{p}$ & $0.111^{*}$ & $0.006^{*}$ & $0.460^{*}$ & $0.001^{*}$ \\
\hline
\end{tabular}

$\mathrm{SPH}_{\mathrm{AB}}{ }^{1}$ : Spherical aberration; HOA's²: High-order aberration; *Independent T Test. 
$(p=0.006)$. Mean total higher-order aberration values were $0.29 \pm 0.10 \mu \mathrm{m}$ in the myopic, and $0.42 \pm 0.14 \mu \mathrm{m}$ in the astigmatic group $(\mathrm{p}=0.001)$.

With contact lens the mean corneal wavefront aberration values were as follows (Table 4). The mean spherical aberration RMS values were $0.10 \pm 0.17$ $\mu \mathrm{m}$ in the myopic, and $0.10 \pm 0.23 \mu \mathrm{m}$ in the astigmatic groups $(p=0.85)$. Mean trefoil values were $0.13 \pm 0.09 \mu \mathrm{m}$ in the myopic, and $0.17 \pm 0.12 \mu \mathrm{m}$ in the astigmatic groups $(p=0.20)$. Mean coma values were $0.16 \pm 0.06 \mu \mathrm{m}$ in the myopic, and $0.20 \pm 0.13$ $\mu \mathrm{m}$ in the astigmatic groups $(\mathrm{p}=0.120)$. Mean total higher-order aberration values were $0.33 \pm 0.10 \mu \mathrm{m}$ in the myopic, and $0.37 \pm 0.23 \mu \mathrm{m}$ in the astigmatic groups $(\mathrm{p}=0.278)$.

When we compared the mean RMS values of spherical aberration and trefoil values, we did not observe any statistically significant difference between myopic and astigmatic groups as for on- and off-eyes ( $p>0.05)$. Off-eye mean coma and total higher-order aberration RMS values were significantly higher in the astigmatic group relative to the myopic group $(p=0.006, p=0.001)$ but on-eye mean RMS values did not show any statistically significant difference between two groups ( $p>0.05)$.

\section{DISCUSSION}

Myopia and astigmatism constitute major classes of refractive errors [14]. Patients usually suffer from blurred vision and astenopic complaints due to their uncorrected refractive errors. Reducing higher-order aberrations is a new currently entertained phenomenon in ophthalmology aiming at increasing the retinal image quality $[3,8]$. Previ- ous studies showed that HOAs had significant negative correlations with visual performance, and coma-like aberration of the eye significantly influences contrast sensitivity function in normal human eyes [15].

Levy et al. investigated higher-order aberrations in patients with supernormal vision without any correction and found no difference between myopic and normal eyes [16]. In our study we found significantly higher values in coma and total higher-order aberration in astigmatic patients, without contact lens fitting. But after contact lens application, there was no significant difference between myopic and astigmatic groups. Richdale et al. studied low to moderate astigmatic patients wearing toric and spheric equivalent contact lenses and found better results in visual acuity values with toric lenses than spherical lenses [17].

Several studies reported different results about relationships between contrast sensitivity and contact lens which can be attributed to different conditions including contact lens material, contact lens type, adequate fitting of contact lens, and pupil size of the patients. For instance Cox et al. [18] reported in their study that soft contact lenses may induce spherical aberrations which could be the reason of contrast sensitivity loss in $6 \mathrm{~mm}$ - sized pupils, Grey et al. [19] reported reductions in contrast sensitivity in the previous soft contact lens wearers whose lenses were made of hydrogel material. Also Wei et al. [20] reported that rigid gas permeable lenses improved visual acuity significantly but contrast sensitivity was reduced in keratokonic patients. We have found a significant increase in low-contrast sensitivity values after contact lens application in

TABLE 4. Comparison of on-eye aberration values according to the groups

\begin{tabular}{lcccc} 
SPH AB & Coma & Trefoil & Total & HOA's $^{2}$ \\
\hline Myopic group & $0.10 \pm 0.17 \mu \mathrm{m}$ & $0.16 \pm 0.06 \mu \mathrm{m}$ & $0.13 \pm 0.09 \mu \mathrm{m}$ & $0.33 \pm 0.10 \mu \mathrm{m}$ \\
Astigmatic group & $0.10 \pm 0.23 \mu \mathrm{m}$ & $0.20 \pm 0.13 \mu \mathrm{m}$ & $0.17 \pm 0.12 \mu \mathrm{m}$ & $0.37 \pm 0.23 \mu \mathrm{m}$ \\
$\mathrm{p}$ & $0.847 *$ & $0.120 *$ & $0.202^{*}$ & $0.278^{*}$ \\
\hline
\end{tabular}

$\mathrm{SPH}_{\mathrm{AB}}{ }^{1}$ : Spherical aberration; $\mathrm{HOA}^{2} \mathrm{~s}^{2}$ : High-order aberration; ${ }^{*}$ Independent T Test. 
both groups However when we compared on-eye and off-eye results there were no significant differences between the two groups and after contact lens fitting the contrast sensitivity values were sufficient and satisfactory for both goups.

Roberts et al. investigated higher-order aberrations in myopic patients and found that soft contact lenses induced relatively higher-order aberrations, and $\mathrm{Lu}$ et al. reported similar results on monochromatic aberrations in human eyes with contact lenses $[21,7]$. The induction of wavefront aberrations for soft-CL lenses has been explained by several factors including decentration of the soft-CL relative to the pupil center, surface deformation due to the too-steep base curvature, and a complex interaction between the tear film and the contact lenses on the irregular corneal surface [22, 23]. Lu et al. [7] has also showed that contact lenses induce relatively higher-order aberrations on the eyes that have low wavefront aberrations. Our findings support their findings because we also observed a slight induction of higher-order aberrations in the myopic patients with low level of aberrations while we found a decrease in corneal higher-order aberrations in the astigmatic group with a higher level of baseline corneal higher-order aberrations. In our study, visual acuities and contrast sensitivity values were satisfactory for all of the patients with both aspheric and toric soft lenses.

Our study has several limitations. Firstly, we only evaluated aspheric Balafilcon A lenses in comparison with the toric lenses of the same brand in the astigmatic eyes. Other types of spheric and toric lenses could have yielded different results. Another limitation of our study is our small sample size. Prospective and large- sized studies comparing different types of contact lenses may be helpful in the future.

\section{CONCLUSION}

Myopic and astigmatic patients differ in terms of high- order aberrations and these differences cannot be equalized after contact lens application, but visual quality can be improved in both patients by using contact lenses.
Conflict of Interest: No conflict of interest was declared by the authors.

Financial Disclosure: The authors declared that this study has received no financial support.

\section{REFERENCES}

1. Lombardo M, Lombardo G. Wave aberration of human eyes and new descriptors of image optical quality and visual performance. J Cataract Refract Surg 2010;36:313-31. CrossRef

2. Marcos S. Aberrometry: basic science and clinical applications. Bull Soc Belge Ophtalmol 2006;302:197-213.

3. Yoon GY, Williams DR. Visual performance after correcting the monochromatic and chromatic aberrations of the eye. J Opt Soc Am A Opt Image Sci Vis 2002;19:266-75. CrossRef

4. Liang J, Williams DR. Aberrations and retinal image quality of the normal human eye. J Opt Soc Am A Opt Image Sci Vis 1997;14:2873-83. CrossRef

5 Moreno-Barriuso E, Marcos S, Navarro R, Burns SA. Comparing laser ray tracing, the spatially resolved refractometer, and the Hartmann-Shack sensor to measure the ocular wave aberration. Optom Vis Sci 2001;78:152-6. CrossRef

6. Berntsen DA, Merchea MM, Richdale K, Mack CJ, Barr JT. Higher-order aberrations when wearing sphere and toric soft contact lenses. Optom Vis Sci 2009;86:115-22. CrossRef

7. Lu F, Mao X, Qu J, Xu D, He JC. Monochromatic wavefront aberrations in the human eye with contact lenses. Optom Vis Sci 2003;80:135-41. CrossRef

8. Edwards G. Soft lens correction of higher-order aberration Contact Lens Spectrum, Issue: July 2006.

9. Torrents A, Gispets J, Pujol J. Double-pass measurements of retinal image quality in monofocal contact lens wearers. Ophthalmic Physiol Opt 1997;17:357-66. CrossRef

10. Hong X, Himebaugh N, Thibos LN. On-eye evaluation of optical performance of rigid and soft contact lenses. Optom Vis Sci 2001;78:872-80. CrossRef

11. De Brabander J, Chateau N, Bouchard F, Guidollet S. Contrast sensitivity with soft contact lenses compensated for spherical aberration in high ametropia. Optom Vis Sci 1998;75:37-43. CrossRef

12. Harvey B, Long B. The optics of soft toric fitting; vision through contact lenses. Optician 2003;226:20-5.

13. Chen L, Artal P, Gutierrez D, Williams DR. Neural compensation for the best aberration correction. J Vis 2007;7:9.1-9.

14. Rohul J, Maqbool A, Hussain SA, Shamila H, Anjum F, Hamdani ZA. Prevalence of refractive errors in adolescents in out-patient attendees of the preventive ophthalmology Clinıc Of Community Medicıne, Skıms, Kashmır, India. NUJHS 2013;1:17-20.

15. Oshika T, Okamoto C, Samejima T, Tokunaga T, Miyata K. Contrast sensitivity function and ocular higher-order wavefront aberrations in normal human eyes. Ophthalmology 2006;113:1807-12. CrossRef

16. Levy Y, Segal O, Avni I, Zadok D. Ocular higher-order aber- 
rations in eyes with supernormal vision. Am J Ophthalmol 2005;139:225-8. CrossRef

17. Richdale K, Berntsen DA, Mack CJ, Merchea MM, Barr JT. Visual acuity with spherical and toric soft contact lenses in low - to moderate-astigmatic eyes. Optom Vis Sci 2007;84:969-75. CrossRef

18. Cox I, Holden BA. Soft contact lens-induced longitudinal spherical aberration and its effect on contrast sensitivity. Optom Vis Sci 1990;67:679-83. CrossRef

19. Grey CP. Changes in contrast sensitivity during the first hour of soft lens wear. Am J Optom Physiol Opt 1986;63:702-7. CrossRef

20. Wei RH, Khor WB, Lim L, Tan DT. Contact lens characteristics and contrast sensitivity of patients with keratoconus. Eye Contact Lens 2011;37:307-11. CrossRef

21. Roberts B, Athappilly G, Tinio B, Naikoo H, Asbell P. Higher order aberrations induced by soft contact lenses in normal eyes with myopia. Eye Contact Lens 2006;32:138-42. CrossRef

22. He JC, Gwiazda J, Thorn F, Held R. Wave-front aberrations in the anterior corneal surface and the whole eye. J Opt Soc Am A Opt Image Sci Vis 2003;20:1155-63. CrossRef

23. Artal P, Guirao A, Berrio E, Williams DR. Compensation of corneal aberrations by the internal optics in the human eye. J Vis 2001;1:1-8. CrossRef 